\title{
Production and testing of the ENEA-Bologna VITJEFF32.BOLIB (JEFF-3.2) multi-group (199 $n+42$ y) cross section library in AMPX format for nuclear fission applications
}

\author{
Massimo Pescarini ${ }^{*}$, Roberto Orsi, and Manuela Frisoni \\ ENEA, Italian National Agency for New Technologies, Energy and Sustainable Economic Development, \\ "E. Clementel" Research Centre, I-40129 Bologna, Italy
}

\begin{abstract}
The ENEA-Bologna Nuclear Data Group produced the VITJEFF32.BOLIB multi-group coupled neutron/photon (199 $n+42 \gamma)$ cross section library in AMPX format, based on the OECD-NEA Data Bank JEFF-3.2 evaluated nuclear data library. VITJEFF32.BOLIB was conceived for nuclear fission applications as European counterpart of the ORNL VITAMIN-B7 similar library (ENDF/B-VII.0 data). VITJEFF32.BOLIB has the same neutron and photon energy group structure as the former ORNL VITAMIN-B6 reference library (ENDF/B-VI.3 data) and was produced using similar data processing methodologies, based on the LANL NJOY-2012.53 nuclear data processing system for the generation of the nuclide cross section data files in GENDF format. Then the ENEA-Bologna 2007 Revision of the ORNL SCAMPI nuclear data processing system was used for the conversion into the AMPX format. VITJEFF32.BOLIB contains processed cross section data files for 190 nuclides, obtained through the Bondarenko (f-factor) method for the treatment of neutron resonance self-shielding and temperature effects. Collapsed working libraries of self-shielded cross sections in FIDO-ANISN format, used by the deterministic transport codes of the ORNL DOORS system, can be generated from VITJEFF32.BOLIB through the cited SCAMPI version. This paper describes the methodology and specifications of the data processing performed and presents some results of the VITJEFF32.BOLIB validation.
\end{abstract}

\section{Introduction}

In the last two decades, the three-dimensional (3D) deterministic discrete ordinates $\left(\mathrm{S}_{\mathrm{N}}\right)$ transport codes using group-wise cross section libraries extended their practical simulation capability to an enlarged variety of nuclear systems with different neutron spectra and high geometrical complexity. In particular they increased their competitiveness with respect to the 3D Monte Carlo codes in radiation shielding and damage safety analyses in nuclear fission reactor applications. Comparable or even more convenient performances in terms of CPU times were in fact obtained with the same calculation precision, similar description capability of complex geometries, suitable simulation of different neutron and photon spectral conditions. Various factors concurred to determine specifically the increased flexibility and convenience of the 3D SN codes: 1) the impressive increased performance of modern computers, 2) innovative fine-group pseudo-problem-independent cross section libraries with upscatter cross sections, 3 ) new ancillary pre/post-processor systems of programs dedicated to $2 \mathrm{D}$ and $3 \mathrm{D}$ deterministic transport codes and 4) no need to justify, as in the case of the Monte Carlo codes, the statistics adopted with respect to the requirements of the nuclear safety authorities. For example the ORNL VITAMIN-B6 [1] (ENDF/B-VI.3 [2] data; ORNL, 1996), the ORNL VITAMIN-B7 [3]
(ENDF/B-VII.0 [4] data; ORNL, 2011) and the ENEABologna VITJEFF311.BOLIB [5] (JEFF-3.1.1 [6] [7] data; ENEA-Bologna, 2011) are examples of libraries of the cited type, based on the Bondarenko [8] method for neutron resonance self-shielding and temperature effects. Concerning the ancillary systems to the $\mathrm{S}_{\mathrm{N}}$ transport codes, the free availability, since 2001 of the ENEABologna BOT3P system, based on combinatorial geometry algorithms, it is underlined here. BOT3P, now available in the BOT3P-5.3 [9] version, can be used in particular for the automatic generation and the graphical verification of the spatial mesh grids of the geometrical model of the following $\mathrm{S}_{\mathrm{N}} 3 \mathrm{D}$ transport codes: TORT3.2 [10] (ORNL DOORS [11] system], LANL PARTISN [12], KATRIN (KIAM CNCSN 2009 [13] system) and the commercial code RAPTOR-M3G [14], currently used [15] by Westinghouse together with BOT3P. Up to recent times, only the 3D Monte Carlo codes could obtain satisfactory results with high calculation precision in the description of complex geometries. At present, with the recent availability of the cited ancillary pre/post-processor systems, the $3 \mathrm{D} \mathrm{S}_{\mathrm{N}}$ codes increased dramatically their geometrical simulation capability and this induced an increased interest to give more availability of updated group-wise cross section libraries. This is justified both in terms of the previously cited fine-group coupled $\mathrm{n} / \gamma$ pseudoproblem-independent mother libraries and broad-group

Corresponding author: massimo.pescarini@enea.it 
coupled $n / \gamma$ working libraries with parameterized sets of self-shielded cross sections for a specific type of fission reactor, obtained through problem dependent cross section collapsing from the previously cited fine-group mother libraries. Examples of broad-group working libraries for LWR shielding and pressure vessel dosimetry applications are: BUGLE-96 [1] derived from VITAMIN-B6, BUGLE-B7 [3] from VITAMIN-B7 and BUGJEFF311.BOLIB [16] from VITJEFF311.BOLIB. BUGJEFF311.BOLIB is in particular the first BUGLE96-type freely released working library based on JEFF data. This is the background which encouraged the ENEA-Bologna Nuclear Data Group to continue the generation of updated fine-group cross section libraries of VITAMIN-B6-type and derived collapsed working libraries of BUGLE-96-type in the group structures and data processing methodology presently recommended by the US ANSI/ANS-6.1.2-1999 (R2009) [17] standard. In the present paper in particular the generation of the VITJEFF32.BOLIB [18] fine-group coupled neutron and photon (199n $+42 \gamma)$ cross section library in AMPX format for nuclear fission applications, based on the OECD-NEA Data Bank JEFF-3.2 most updated evaluated nuclear data library, is described.

\section{Processing codes and procedures}

The VITJEFF32.BOLIB library was derived (see Figs. 1 and 2 and Table 1) from cross section data files in GENDF format, generated through the LANL NJOY2012.53 [19] nuclear data processing system. The following modules of NJOY were used to process neutron interaction (n-n), gamma-ray production $(n-\gamma)$ and gamma-ray interaction $(\gamma-\gamma)$ data, from the JEFF-3.2 incident neutron and photo-atomic data in ENDF-6 format into the GENDF format. Specifically, the MODER, RECONR, BROADR, THERMR, HEATR, GASPR, PURR, GROUPR modules were used for the incident neutron data while the MODER, RECONR and GAMINR modules were used for the photo-atomic data. Then the revised version of the SMILER module of the ENEA-Bologna 2007 Revision [20] of the ORNL SCAMPI [21] nuclear data processing system was used to translate the multi-group data from the GENDF format into the AMPX master library format of VITJEFF32.BOLIB. It is underlined that, in particular, this ENEA revised version of SMILER permits to obtain separately the prompt fission spectrum $(\mathrm{MF}=6$ and $\mathrm{MT}=18)$, the delayed fission spectrum $(\mathrm{MF}=5$ and $\mathrm{MT}=455$ ) or the total fission spectrum needed for fixed source transport calculations, differently from the original ORNL SMILER version, used to generate VITAMIN-B6, which permits to obtain only the prompt component. Then the module AIM of SCAMPI was used to convert the master cross section library from binary to BCD format. The availability of VITJEFF32.BOLIB permits now to collapse new updated self-shielded broad-group working cross section libraries which, e.g., can be produced in the FIDO-ANISN format with the previously cited ENEA-Bologna 2007 Revision of SCAMPI from VITJEFF32.BOLIB. More specifically, the cross sections in AMPX format can be collapsed through the MALOCS module, can be self-shielded through the BONAMI module and finally can be produced into the AMPX or FIDO-ANISN formats. The cross sections in AMPX format can be used by the XSDRNPM code $\left(1 \mathrm{D} \mathrm{S}_{\mathrm{N}}\right)$, included in the SCAMPI or in the SCALE [22] systems. Moreover the cross sections in FIDO-ANISN format can be used for example by the discrete ordinates $\left(\mathrm{S}_{\mathrm{N}}\right)$ transport codes ANISN-ORNL (1D), DORT (2D) and TORT (3D) of the DOORS system of deterministic codes. The present calculations were performed on a Personal Computer (CPU INTEL Pentium III, 448 MB of RAM; FSF-g77 version 0.5.26 FORTRAN compiler for NJOY and $\mathrm{f77}$ Absoft version 5.0 FORTRAN 77 compiler for SCAMPI) with the Linux Red Hat 7.1 operative system.

\section{Library specifications}

A set of 190 JEFF-3.2 cross section data files was processed for the VITJEFF32.BOLIB library. The increased number of materials with respect to the VITAMIN-B6 (120 materials) library is mainly caused by the almost complete availability of isotopic data files in the JEFF-3.2 evaluated nuclear data library in substitution of natural element data files. The Bondarenko (f-factor) method was used for handling resonance self-shielding and temperature effects. As for VITAMIN-B6, all the 184 standard (not bound) nuclides were processed at 4 temperatures $(300 \mathrm{~K}, 600 \mathrm{~K}, 1000 \mathrm{~K}$ and $2100 \mathrm{~K}$ ). Concerning the background cross section $\sigma_{0}$ values adopted, a conservative choice was performed with respect to both ORNL VITAMIN-B7 and VITAMIN-B6 libraries. Differently from VITAMIN-B6 and similarly to VITAMIN-B7, each standard nuclide was processed with the same set of twelve values $(1.0 \mathrm{E}$ $06,0.01,1,10,50,100,300,1000,1.0 \mathrm{E}+04,1.0 \mathrm{E}+05$, $1.0 \mathrm{E}+06$ and $1.0 \mathrm{E}+10$ barns) for $\sigma_{0}$. In particular the $1.0 \mathrm{E}+10$ value corresponds to the infinite dilution background cross section whereas $1.0 \mathrm{E}-06$ represents the total self-shielding value. This approach, i.e. the same set of twelve background cross sections for each standard nuclide, was more similar to that employed in the VITAMIN-B7 generation but, in addition to the values used for the data processing of VITAMIN-B7, the $1.0 \mathrm{E}-06$ and 0.01 values were included. The $1.0 \mathrm{E}-06$ value was chosen as near as possible to 0.0 (in line with the values used in the past for getting close to 0.0), according to the previously generated OECD-NEADB VITAMIN-J [23] library. Concerning then the 0.01 value, it is underlined that this additional $\sigma_{0}$ numerical value improves further (see [24]), for example, the neutron cross section self-shielding of Fe-56 in natural iron and of Co-59 (only isotope in natural cobalt), through a more precise self-shielding factor interpolation. Thermal scattering cross sections were produced for six additional bound nuclides which were processed at all the temperatures available in the JEFF3.2 thermal scattering law data file which is the same as the ones included in the JEFF-3.1.2, JEFF-3.1.1 and JEFF-3.1 evaluated nuclear data libraries: H-1 in light 


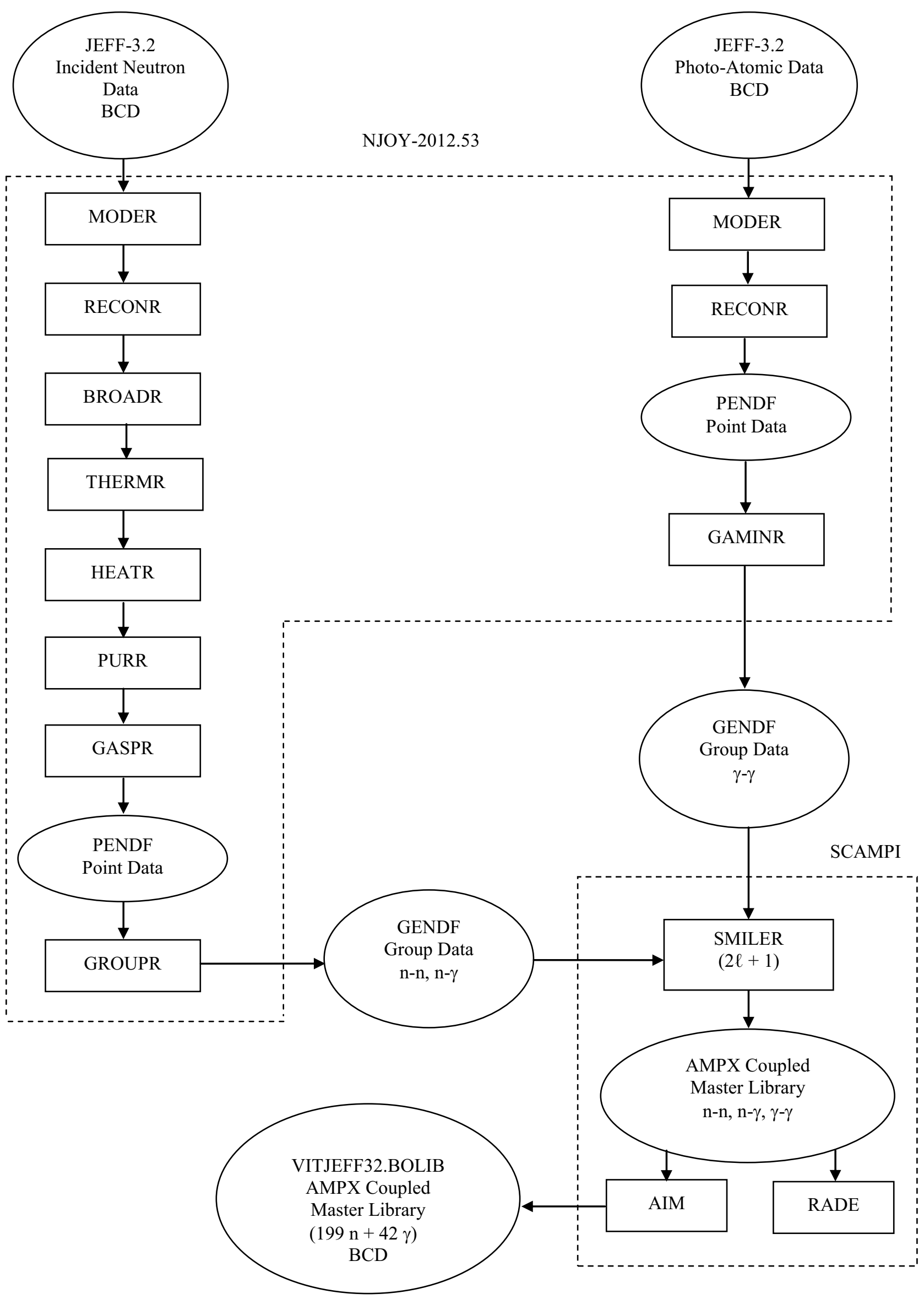

Fig. 1. Procedure for generating the VITJEFF32.BOLIB standard nuclides in AMPX format from JEFF-3.2. 


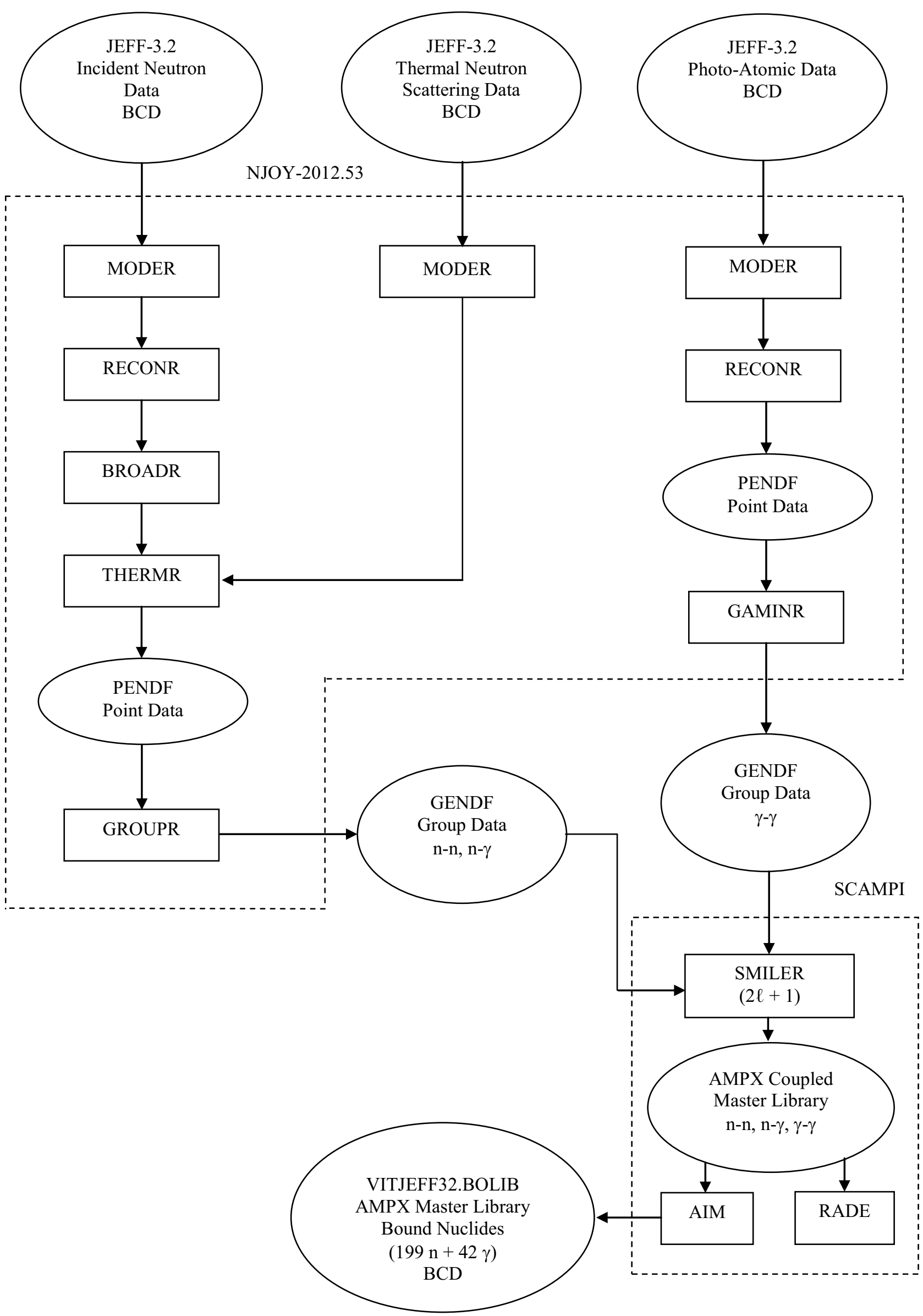

Fig. 2. Procedure for generating the VITJEFF32.BOLIB bound nuclides in AMPX format from JEFF-3.2. 
Table 1. Modules from the NJOY-2012.53 and SCAMPI nuclear data processing systems used to process VITJEFF32.BOLIB. NJOY-2012.53 System

\begin{tabular}{ll} 
Module & \multicolumn{1}{c}{ Function } \\
\hline MODER & Converts between ENDF standard coded mode and the NJOY blocked binary mode. \\
RECONR & Reconstructs point-wise cross sections from JEFF resonance parameters and interpolation schemes. \\
BROADR & Doppler-broadens and thins point-wise cross sections. \\
THERMR & Produces cross sections and energy-to-energy matrices for free or bound scatterers in the thermal energy range. \\
HEATR & Generates heat production cross sections (KERMA factors) and damage-energy production. \\
GASPR & Computes gas production cross sections. \\
PURR & $\begin{array}{l}\text { Computes probability tables and effective point-wise self-shielded cross sections in the unresolved energy } \\
\text { range. }\end{array}$ \\
GROUPR & $\begin{array}{l}\text { Generates self-shielded multi-group cross sections and group-to-group scattering and photon production } \\
\text { matrices in GENDF format. } \\
\text { GAMINR }\end{array}$
\end{tabular}

SCAMPI System (ENEA-Bologna 2007 Revision)

Module Function

$\begin{array}{ll}\text { SMILER } & \text { Translates GENDF files produced by NJOY into AMPX master interface format. } \\ \text { RADE } & \text { Performs sanity and consistency tests on multi-group libraries. } \\ \text { AIM } & \text { Converts master cross section libraries from binary format to BCD (or vice-versa). }\end{array}$

water, $\mathrm{H}-1$ in polyethylene, $\mathrm{H}-1$ in zirconium hydride (not contained in the VITAMIN-B6 library), $\mathrm{H}-2$ in heavy water, $\mathrm{C}$ in graphite and $\mathrm{Be}$ in beryllium metal. VITJEFF32.BOLIB adopts the same problemindependent group structure of the VITAMIN-B6 library with 199 neutron and 42 photon energy groups, able to treat not only "fast" but also "thermal" neutron (water or graphite-moderated) reactor systems, through the adequate group structure at lower energies. It is underlined that the thermal neutron energy range below $5.043 \mathrm{eV}$, i.e. the range of the groups which include upscatter, contains 36 groups. The photon energy group structure includes the top energy group with uppermost limit extended to $30 \mathrm{MeV}$. The neutron and photon weighting functions are the same as in VITAMIN-B6. The neutron weighting function is of the form typically chosen for fission reactor shielding problems, i.e. it consists of a smoothly varying combination of the following neutron spectra:

1. Maxwellian thermal spectrum $(\mathrm{kT}=0.025 \mathrm{eV})$ $\mathrm{W}_{1}(\mathrm{E})=\mathrm{C}_{1} \mathrm{Ee}^{-\mathrm{E} / \mathrm{kT}}$ from $1.0 \mathrm{E}-5 \mathrm{eV}$ to $0.125 \mathrm{eV}$;
2. 1/E slowing down spectrum $\mathrm{W}_{2}(\mathrm{E})=\mathrm{C}_{2} / \mathrm{E}$ from $0.125 \mathrm{eV}$ to $820.8 \mathrm{keV}$;

3. Fission spectrum $(\theta=1.273 \mathrm{MeV})$ $\mathrm{W}_{3}(\mathrm{E})=\mathrm{C}_{3} \mathrm{E}^{1 / 2} \mathrm{e}^{\mathrm{E} / \theta}$ from $820.8 \mathrm{keV}$ to $20 \mathrm{MeV}$.

This corresponds to an IWT $=4$ option in GROUPR with the $\mathrm{C}_{1}, \mathrm{C}_{2}$ and $\mathrm{C}_{3}$ constants assuring the continuity of the spectrum function. The fission temperature $\theta$ has been adjusted to better reflect the neutron spectrum in a thermal reactor $(\theta=1.273 \mathrm{MeV}$ versus $\theta=1.41 \mathrm{MeV}$ for the VITAMIN-E [25] library dedicated to fast fission and fusion applications). The photon weighting spectrum consists of a $1 / \mathrm{E}$ spectrum with a "roll-off" of the spectrum at lower energies to represent photoelectric absorption and a similar drop-off of the spectrum at higher energies corresponding to the Q-value for neutron capture. This corresponds to the IWT $=3$ option in GAMINR. In VITJEFF32.BOLIB the order of scattering used for both neutrons and photons is P7, for nuclides with $Z=1$ through $Z=30$ (zinc) and $P 5$ for the remainder of the nuclides. The numerical values of the fractional error 
tolerances in NJOY for both the libraries, $0.1 \%$ for resolved resonance reconstruction and for linearization in RECONR and $0.1 \%$ for thinning in BROADR, were reduced with respect to the $0.2 \%$ corresponding values in VITAMIN-B6. About the available neutron fission spectra, the total (prompt + delayed) neutron fission spectra $\chi$ for U-235, U-238 and Pu-239, obtained from the specific GENDF files through the previously cited ENEA-Bologna version of SMILER and the ICE modules of SCAMPI, were included in tabulated form into each package of the two libraries. It is underlined that the corresponding data in VITAMIN-B6 include only the prompt spectrum components.

\section{Examples of library validation}

VITJEFF32.BOLIB was extensively tested on about 80 thermal, intermediate and fast spectrum neutron criticality benchmark experiments. The experimental details (geometry, composition and k-effective) were taken from the ICSBEP Handbook [26]. The data processing of the problem-dependent working cross section libraries and the transport calculations were performed using the ENEA-Bologna 2007 Revision of SCAMPI. In particular, the BONAMI module generated the neutron self-shielded cross section working libraries and the XSDRNPM 1D discrete ordinates $\left(\mathrm{S}_{\mathrm{N}}\right)$ transport module calculated the k-effective $\left(\mathrm{k}_{\mathrm{eff}}\right)$ results. All the calculations were performed in spherical geometry, in the $\mathrm{P}_{5}-\mathrm{S}_{16}$ approximation. In particular, $\mathrm{P}_{5}$ corresponds to $\mathrm{L}=\ell$-max, the maximum order of the Legendre polynomial $\left(\mathrm{P}_{\ell}\right)$ expansion of the scattering cross section matrices and $\mathrm{S}_{16}$ represents the order of the flux angular discretization.

The $\mathrm{k}_{\text {eff }}$ results obtained with VITJEFF32.BOLIB were compared with the corresponding results calculated using the VITJEFF311.BOLIB library, previously processed in ENEA-Bologna through NJOY-99.259 [27].

A simplified data processing and validation flow-chart of the VITJEFF32.BOLIB library is shown in Fig. 3.

A partial set of k-effective results for metallic fast neutron spectrum criticality benchmark experiments is presented in Table 2, where the most relevant differences between the results obtained from the VITJEFF32.BOLIB and VITJEFF311.BOLIB libraries were found.

Following the denominations reported in the ICSBEP handbook, the k-effective results, obtained in the 1D transport calculations using the VITJEFF32.BOLIB library and reported in Table 2, refer to HEU (Highly Enriched Uranium) benchmark experiments, to U-233 benchmark experiments and to Pu-239 benchmark experiments. The following acronyms are used in the cited table: NU (natural uranium), DU (depleted uranium) and WC (wolfram carbide or tungsten carbide).

It is underlined that in the ICSBEP Handbook the assumption of a normal probability distribution for the $\mathrm{k}_{\text {eff }}$ values of the "experimental or benchmark-model" configurations is considered usually reasonable. Consequently the $\mathrm{k}_{\text {eff }}$ values reported in Table 2 are the mean values of the assumed normal distributions and their associated uncertainties $\pm \Delta \mathrm{k}_{\text {eff }}$ correspond to one standard deviation $(1 \sigma)$ which represents a confidence level with $68 \%$ probability that the measurement result is contained within $\pm 1 \sigma$.

The VITJEFF32.BOLIB HEU-MET-FAST $\mathrm{k}_{\text {eff }}$ results present a systematic increase ranging from about 100 to about $700 \mathrm{pcm}$ and are in general less adherent to the experimental results with respect to the corresponding results obtained with VITJEFF311.BOLIB. On the other hand the results obtained using VITJEFF32.BOLIB are almost always overestimated with respect to the corresponding $\mathrm{k}_{\mathrm{eff}}$ experimental results.

The VITJEFF32.BOLIB U-233-MET-FAST $\mathrm{k}_{\text {eff }}$ results appear systematically lower of about $200 \div 400 \mathrm{pcm}$ and more adherent to the experimental results with respect to the corresponding results obtained with VITJEFF311.BOLIB. On the other hand the results obtained using VITJEFF32.BOLIB are systematically overestimated with respect to the corresponding $\mathrm{k}_{\text {eff }}$ experimental results.

The VITJEFF32.BOLIB PU-MET-FAST $\mathrm{k}_{\text {eff }}$ results appear systematically higher of about $100 \div 300 \mathrm{pcm}$ and in general less adherent to the experimental results with respect to the corresponding results obtained with VITJEFF311.BOLIB. The results obtained using VITJEFF32.BOLIB are in general overestimated with respect to the corresponding $\mathrm{k}_{\mathrm{eff}}$ experimental results.

It is underlined that all the cited results are always contained within a confidence level of the total experimental error of $\pm 3 \sigma(99.7 \%$ probability that the measurement result is between \pm 3 standard deviations).

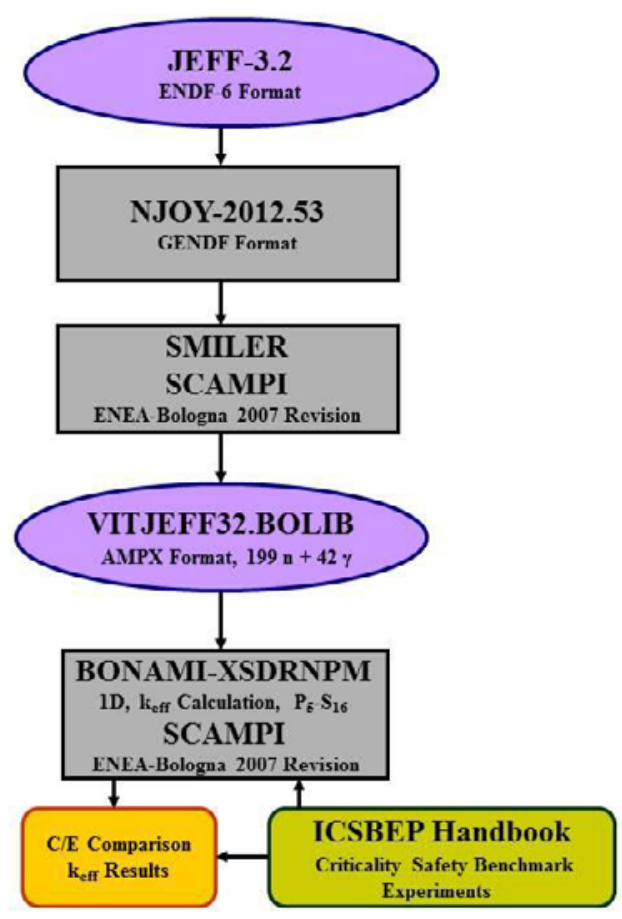

Fig. 3. Simplified data processing and validation flow-chart of the VITJEFF32.BOLIB Library. 
Table 2. k-effective calculated results for metallic criticality safety benchmark experiments with fast neutron spectrum.

\begin{tabular}{|c|c|c|c|c|c|}
\hline $\begin{array}{l}\text { ICSBEP Handbook } \\
\text { Benchmark Name }\end{array}$ & Reflector & $\begin{array}{c}\text { Experimental } \\
\text { or Benchmark- } \\
\text { Model } \\
\mathrm{k}_{\mathrm{eff}} \pm \Delta \mathrm{k}_{\mathrm{eff}}(\mathrm{pcm}) \\
\end{array}$ & Geometry/ $\mathrm{P}_{\mathrm{L}}-\mathrm{S}_{\mathrm{N}}$ & $\begin{array}{c}\text { VITJEFF32. } \\
\text { BOLIB } \\
\mathrm{k}_{\text {eff }}\end{array}$ & $\begin{array}{c}\text { VITJEFF311. } \\
\text { BOLIB } \\
\mathrm{k}_{\mathrm{eff}}\end{array}$ \\
\hline \multicolumn{6}{|c|}{ Highly Enriched Metallic Uranium with Fast Neutron Spectrum } \\
\hline $\begin{array}{l}\text { HEU-MET-FAST-001-001 } \\
\text { (GODIVA) }\end{array}$ & -- & $1.00000 \pm(100)$ & 1D Sph./ P5-S16 & 1.00051 & 0.99533 \\
\hline $\begin{array}{l}\text { HEU-MET-FAST-002-001 } \\
\text { (TOPSY) }\end{array}$ & NU & $1.00000 \pm(300)$ & 1D Sph./ P5-S16 & 1.00779 & 1.00095 \\
\hline HEU-MET-FAST-003-001 & NU (2in) & $1.00000 \pm(500)$ & 1D Sph./ P5-S16 & 0.99865 & 0.99373 \\
\hline HEU-MET-FAST-003-002 & NU (3in) & $1.00000 \pm(500)$ & 1D Sph./ P5-S16 & 0.99887 & 0.99345 \\
\hline HEU-MET-FAST-003-003 & NU (4in) & $1.00000 \pm(500)$ & 1D Sph./ P5-S16 & 1.00415 & 0.99825 \\
\hline HEU-MET-FAST-003-004 & NU (5in) & $1.00000 \pm(300)$ & 1D Sph./ P5-S16 & 1.00269 & 0.99643 \\
\hline HEU-MET-FAST-003-005 & NU (7in) & $1.00000 \pm(300)$ & 1D Sph./ P5-S16 & 1.00742 & 1.00071 \\
\hline HEU-MET-FAST-003-006 & NU (8in) & $1.00000 \pm(300)$ & 1D Sph./ P5-S16 & 1.00776 & 1.00092 \\
\hline HEU-MET-FAST-003-007 & NU (11 in) & $1.00000 \pm(300)$ & 1D Sph./ P5-S16 & 1.00849 & 1.00148 \\
\hline HEU-MET-FAST-003-008 & WC (1.9in) & $1.00000 \pm(500)$ & 1D Sph./ P5-S16 & 1.00461 & 1.00146 \\
\hline HEU-MET-FAST-003-009 & WC (2.9in) & $1.00000 \pm(500)$ & 1D Sph./ P5-S16 & 1.00613 & 1.00364 \\
\hline HEU-MET-FAST-003-010 & WC (4.5in) & $1.00000 \pm(500)$ & 1D Sph./ P5-S16 & 1.01029 & 1.00897 \\
\hline HEU-MET-FAST-003-011 & WC (6.5in) & $1.00000 \pm(500)$ & 1D Sph./ P5-S16 & 1.01479 & 1.01416 \\
\hline HEU-MET-FAST-003-012 & $\mathrm{Ni}(8 \mathrm{in})$ & $1.00000 \pm(500)$ & 1D Sph./ P5-S16 & 1.01172 & 1.00922 \\
\hline HEU-MET-FAST-022-001 & $\mathrm{Al}$ & $1.00000 \pm(190)$ & 1D Sph./ P5-S16 & 1.00005 & 0.99527 \\
\hline HEU-MET-FAST-027-001 & $\mathrm{Pb}$ & $1.00000 \pm(250)$ & 1D Sph./ P5-S16 & 1.00458 & 1.00052 \\
\hline $\begin{array}{l}\text { HEU-MET-FAST-028-001 } \\
\text { (FLATTOP-25) }\end{array}$ & NU & $1.00000 \pm(300)$ & 1D Sph./ P5-S16 & 1.00895 & 1.00218 \\
\hline HEU-MET-FAST-057-001 & $\mathrm{Pb}$ & $1.00000 \pm(200)$ & 1D Sph./ P5-S16 & 0.99684 & 0.99425 \\
\hline HEU-MET-FAST-057-002 & $\mathrm{Pb}$ & $1.00000 \pm(230)$ & 1D Sph./ P5-S16 & 1.00437 & 1.00122 \\
\hline \multicolumn{6}{|c|}{ Metallic U-233 with Fast Neutron Spectrum } \\
\hline $\begin{array}{l}\text { U233-MET-FAST-001-001 } \\
\text { (JEZEBEL-233) }\end{array}$ & -- & $1.00000 \pm(100)$ & 1D Sph./.P5-S16 & 1.00083 & 1.00383 \\
\hline U233-MET-FAST-002-001 & HEU & $1.00000 \pm(100)$ & 1D Sph./.P5-S16 & 1.00011 & 1.00257 \\
\hline U233-MET-FAST-002-002 & HEU & $1.00000 \pm(110)$ & 1D Sph./.P5-S16 & 1.00166 & 1.00342 \\
\hline U233-MET-FAST-003-001 & NU & $1.00000 \pm(100)$ & 1D Sph./.P5-S16 & 1.00189 & 1.00575 \\
\hline U233-MET-FAST-003-002 & NU & $1.00000 \pm(100)$ & 1D Sph./.P5-S16 & 1.00363 & 1.00719 \\
\hline $\begin{array}{l}\text { U233-MET-FAST-006-001 } \\
\text { (FLATTOP-23) }\end{array}$ & NU & $1.00000 \pm(140)$ & 1D Sph./.P5-S16 & 1.00472 & 1.00665 \\
\hline \multicolumn{6}{|c|}{ Metallic Pu-239 with Fast Neutron Spectrum } \\
\hline $\begin{array}{l}\text { PU-MET-FAST-001-001 } \\
\text { (JEZEBEL) }\end{array}$ & -- & $1.00000 \pm(200)$ & 1D Sph./ P5-S16 & 1.00044 & 0.99889 \\
\hline $\begin{array}{l}\text { PU-MET-FAST-002-001 } \\
\text { (JEZEBEL-240) }\end{array}$ & -- & $1.00000 \pm(200)$ & 1D Sph./ P5-S16 & 1.00267 & 1.00277 \\
\hline $\begin{array}{l}\text { PU-MET-FAST-006-001 } \\
\text { (FLATTOP-PU) }\end{array}$ & NU & $1.00000 \pm(300)$ & 1D Sph./ P5-S16 & 1.00642 & 1.00305 \\
\hline $\begin{array}{l}\text { PU-MET-FAST-008-001 } \\
\text { (THOR) }\end{array}$ & Th & $1.00000 \pm(60)$ & 1D Sph./ P5-S16 & 0.99861 & 1.00124 \\
\hline PU-MET-FAST-009-001 & $\mathrm{Al}$ & $1.00000 \pm(270)$ & 1D Sph./ P5-S16 & 1.00468 & 1.00401 \\
\hline PU-MET-FAST-010-001 & $\mathrm{NU}$ & $1.00000 \pm(180)$ & 1D Sph./ P5-S16 & 1.00257 & 1.00091 \\
\hline PU-MET-FAST-011-001 & $\mathrm{H} 2 \mathrm{O}$ & $1.00000 \pm(100)$ & 1D Sph./ P5-S16 & 1.00242 & 0.99943 \\
\hline PU-MET-FAST-018-001 & $\mathrm{Be}$ & $1.00000 \pm(300)$ & 1D Sph./ P5-S16 & 1.00290 & 1.00200 \\
\hline PU-MET-FAST-023-001 & Graphite & $1.00000 \pm(230)$ & 1D Sph./ P5-S16 & 1.00027 & 0.99850 \\
\hline PU-MET-FAST-024-001 & Polyethylene & $1.00000 \pm(200)$ & 1D Sph./ P5-S16 & 1.00227 & 0.99948 \\
\hline PU-MET-FAST-030-001 & Graphite & $1.00000 \pm(210)$ & 1D Sph./ P5-S16 & 1.00439 & 1.00395 \\
\hline PU-MET-FAST-031-001 & Polyethylene & $1.00000 \pm(210)$ & 1D Sph./ P5-S16 & 1.00607 & 1.00385 \\
\hline
\end{tabular}




\section{Conclusion}

The present library was transferred to OECD-NEADB where it received the denomination NEA-1891 ZZ VITJEFF32.BOLIB and is presently in free distribution. The generation of a collapsed working library in FIDOANISN format of self-shielded cross sections into the recommended BUGLE-96 (47 n $+20 \gamma$ energy groups) group structure, dedicated to neutron/photon shielding and LWR pressure vessel dosimetry in nuclear safety transport analyses, can be now performed using the updated JEFF-3.2 data and the ENEA-Bologna 2007 Revision of the SCAMPI system. It is considered important to extend further the availability of group-wise cross section libraries to offer, in particular, to the users of 3D deterministic codes a flexible possibility to generate working cross section libraries based on updated data files. Finally it is noted that the use of the deterministic transport codes together with the necessary multi-group working cross section libraries is often preferred by the industrial organizations that must fulfil quality assurance procedures in reactor safety calculations. In fact there is no need, as in the case of the Monte Carlo codes, to justify the validity of the statistics adopted since the deterministic codes are based on rigorous analytical solutions of the neutral particle transport equations.

\section{References}

1. J.E. White, D.T. Ingersoll, R.Q. Wright, H.T. Hunter, C.O. Slater, N.M. Greene, R.E. MacFarlane, R.W. Roussin, Production and Testing of the Revised VITAMIN-B6 Fine-Group and the BUGLE-96 Broad-Group Neutron/Photon Cross-Section Libraries Derived from ENDF/B-VI.3 Nuclear Data, ORNL, Oak Ridge, ORNL-6795/R1, NUREG/CR6214, Revision 1 (January 1995)

2. P.F. Rose, ENDF/B-VI Summary Documentation, BNL, Brookhaven, BNL-NCS-17541 (ENDF-201) $4^{\text {th }}$ Edition (October 1991)

3. J.M. Risner, D. Wiarda, M.E. Dunn, T.M. Miller, D.E. Peplow, and B.W. Patton, Production and Testing of the VITAMIN-B7 Fine-Group and BUGLE-B7 Broad-Group Coupled Neutron/Gamma Cross-Section Libraries Derived from ENDF/B-VII.0 Nuclear Data, ORNL, Oak Ridge, ORNL/TM2011/12, NUREG/CR-7045 (September 2011)

4. M.B. Chadwick et al., ENDF/B-VII.0: Next Generation Evaluated Nuclear Data Library for Nuclear Science and Technology, Nuclear Data Sheets, Volume 107, Number 12, pp. 2931-3060 (December 2006)

5. M. Pescarini, V. Sinitsa, R. Orsi, VITJEFF311.BOLIB - A JEFF-3.1.1 Multigroup Coupled $(199 n+42 \gamma)$ Cross Section Library in AMPX Format for Nuclear Fission Applications, ENEA-Bologna Technical Report UTFISSM-P9H6003 (November 10, 2011); ENEA-Bologna
Technical Report UTFISSM-P9H6-003 Revision 1 (March 14, 2013)

6. The JEFF-3.1.1 Nuclear Data Library, JEFF Report 22, OECD-NEA Data Bank (2009)

7. The JEFF-3.1 Nuclear Data Library, JEFF Report 21, OECD-NEA Data Bank (2006)

8. I.I. Bondarenko, M.N. Nikolaev, L.P. Abagyan, N.O. Bazaziants, Group Constants for Nuclear Reactors Calculations (Consultants Bureau, New York, 1964)

9. R. Orsi, BOT3P Version 5.3: A Pre/Post-Processor System for Transport Analysis, ENEA-Bologna Technical Report FPN-P9H6-011 (October 22, 2008)

10. W.A. Rhoades, D.B. Simpson, The TORT ThreeDimensional Discrete Ordinates Neutron/Photon Transport Code (TORT Version 3), ORNL, Oak Ridge, ORNL/TM-13221 (October 1997)

11. DOORS3.1: One-, Two- and Three-Dimensional Discrete Ordinates Neutron/Photon Transport Code System, ORNL, Oak Ridge, RSIC Computer Code Collection CCC-650 (August 1996)

12. R.E. Alcouffe, R.S. Baker, J.A. Dahl, S.A. Turner, R. Ward, PARTISN: A Time-Dependent, Parallel Neutral Particle Transport Code System, LANL, Los Alamos, LA-UR-08-07258 (Revised November 2008)

13. A.M. Voloschenko, S.V. Gukov, V.P. Kryuchkov, A.A. Dubinin, O.V. Sumaneev, The CNCSN One-, Two- and Three-Dimensional Coupled Neutral and Charged Particle Discrete Ordinates Code Package, M\&C-2005, Avignon, France (2005)

14. G. Longoni, S.L. Anderson, Reactor Dosimetry Applications Using RAPTOR-M3G: A New Parallel 3-D Radiation Transport Code, ISRD-13, Akersloot, The Netherlands (2008)

15. F.A. Alpan, J.A. Kulesza, Comparison of Standard Light Water Reactor Cross-Section Libraries Using the United States Nuclear Regulatory Commission Pressurized Water Reactor Standard Core Loading Benchmark Problem, ISRD-15, Aix-en-Provence, France (2014)

16. M. Pescarini, V. Sinitsa, R. Orsi, M. Frisoni, BUGJEFF311.BOLIB - A JEFF-3.1.1 Broad-Group Coupled $(47 \mathrm{n}+20 \gamma)$ Cross Section Library in FIDO-ANISN Format for LWR Shielding and Pressure Vessel Dosimetry Applications, ENEABologna Technical Report UTFISSM-P9H6-002, (May 12, 2011); ENEA-Bologna Technical Report UTFISSM-P9H6-002 Revision 1 (March 14, 2013)

17. American National Standard, American Nuclear Society, Neutron and Gamma-Ray Cross Sections for Nuclear Radiation Protection Calculations for Nuclear Power Plants, ANSI/ANS-6.1.2-1999 (Reapproved 2009)

18. M. Pescarini, R. Orsi, M. Frisoni, VITJEFF32.BOLIB - A JEFF-3.2 Multi-Group Coupled (199 n $+42 \gamma)$ Cross Section Library in AMPX Format for Nuclear Fission Applications ENEA-Bologna Technical Report SICNUC-P9H6002 (February 2016)

19. R.E. MacFarlane, D.W. Muir, R.M. Boicourt, A.C. Kahler, The NJOY Nuclear Data Processing System, Version 2012, LANL, Los Alamos, LA-UR-12- 
27079 Rev, Updated for NJOY2012.50 (February 2015).

20. V. Sinitsa, M. Pescarini, ENEA-Bologna 2007 Revision of the SCAMPI (ORNL) Nuclear Data Processing System, ENEA-Bologna Technical Report FPN-P9H6-006 (September 13, 2007)

21. SCAMPI, ORNL, Oak Ridge, RSIC PSR-352, (September 1995). Available from OECD-NEA Data Bank as PSR-0352/06 SCAMPI, last version of the ENEA-Bologna 2007 Revision (see [20]) (July 2015)

22. SCALE: A Comprehensive Modeling and Simulation Suite for Nuclear Safety Analysis and Design, ORNL, Oak Ridge, ORNL/TM-2005/39, Version 6.1 (June 2011)

23. E. Sartori, VITAMIN-J, a 175 Group Neutron Cross Section Library Based on JEF-1 for Shielding Benchmark Calculations, OECD-NEA Data Bank, JEF/DOC-100 Preliminary (October 1985)

24. C. Konno, K. Takakura, K. Kondo, S. Ohnishi, K. Ochiai and S. Sato, Important Remarks on Latest Multigroup Libraries, Progress in Nuclear Science and Technology, Vol. 2, pp. 341-345 (2011)

25. C.R. Weisbin, R.W. Roussin, J.J. Wagschal, J.E. White, R.Q. Wright, VITAMIN-E: An ENDF/B-V Multigroup Cross-Section Library for LMFBR Core and Shield, LWR Shield, Dosimetry and Fusion Blanket Technology, ORNL, Oak Ridge, ORNL5505 (ENDF-274) (February 1979)

26. ICSBEP, OECD-NEA NSC, NEA/NSC/DOC(95)03 (September 2004 Edition)

27. R.E. MacFarlane, NJOY-99, "README0", ORNL, RSIC PSR-0480/02 (December 1999) 